\title{
Serum Apelin and Galactin-3 in Preeclampsia in Iraq
}

\author{
Aamal Sattar Taha ${ }^{1,2}$, Zohreh Zahraei $^{1 *}$,Hussein Kadhem Al-Hakeim ${ }^{3}$ \\ 1 Department of Cell and Molecular Biology, Faculty of Chemistry, University of Kashan, \\ Kashan, Islamic Republic of Iran. E-mail: zahraei@kashanu.ac.ir. \\ ${ }^{2}$ Chemist in a ministry of health in Iraq. E-mail: aamal.satar@yahoo.com. \\ 3 Department of Chemistry, Faculty of Science, Kufa University, Iraq. E-mail: \\ headm2010@yahoo.com.
}

1* Corresponding author: Department of Cell and Molecular Biology, Faculty of Chemistry, University of Kashan, Kashan, 8731751167, Islamic Republic of Iran. Fax: +98-3155912397; Tel: +98-315912396; E-mail: zahraei@kashanu.ac.ir

\section{$\underline{\text { Abstract }}$}

Preeclampsia (PE) is a common pregnancy complication. It is associated with high maternal morbidity and mortality rates and intrauterine foetal growth restriction. This condition is characterised by high blood pressure and urinary protein levels. Apelin and galectin-3 (Gal3) are peptides involved in the regulation of body fluid homeostasis, inflammation and cardiovascular functions. This study aimed to determine the correlations amongst serum apelin and Gal-3 levels and insulin resistance (IR) in women with PE. Sixty patients with PE and 30 healthy controls participated in this study. The PE group had significantly lower apelin levels ( $\mathrm{p}$ $<0.01)$ and higher Gal-3 levels $(\mathrm{p}<0.05)$ than the control group. The PE group had higher serum glucose levels and $\beta$-cell functions than the control group. Moreover, patients with PE exhibited dyslipidaemia. Correlation analysis indicated that apelin and Gal-3 levels were not significantly correlated. Moreover, no correlation existed between the apelin levels and any measured parameters of the PE group. In conclusion, the elevations in serum Gal-3 levels with increments in IR-related parameters and lipid profiles reflect the possible contribution of Gal-3 to the harmful effects of IR and dyslipidemia levels on women with PE. 
Keywords: Apelin; Galectin-3; Preeclampsia; Insulin resistance; Lipid profile.

\section{$\underline{\text { Introduction }}$}

Preeclampsia (PE) is pregnancy disorder that characterised by high blood pressure (BP) and urinary protein levels. It is a common complication encountered in the third trimester of pregnancy and is associated with high maternal morbidity and mortality rates and intrauterine foetal growth restriction. PE is a pregnancy-specific multisystem disorder that features reduced placental perfusion, vascular endothelial dysfunction and coagulation cascade activation [1]. Women with PE are prone to heart diseases [2] because this disorder is associated with inflammation [3]. Therefore, the discovery of novel biomarkers for inflammation and heart diseases in women with PE remains relevant and necessary. The levels of apelin, a peptide involved in the regulation of body fluid homeostasis and cardiovascular functions [4], are elevated in patients with insulin resistance (IR) [5].

Gilbert reviewed studies that identified apelin as an important contributor to the regulation of fluid balance disturbances and cardiovascular disorders in women with PE [6]. Numerous immunological and vascular issues have been associated with apelin. For example, the apelin content of the human placental chorionic villi of women with PE was lower than that of the human placental chorionic villi of women with normal pregnancies [7]. Apelin levels can reflect the cardiovascular changes experienced by pregnant women without PE [8]. Therefore, the apelin levels of women with PE must be studied to identify the factors that affect the health of these women.

Galectin-3 (Gal-3) is a protein secreted by various cells, tissues, organs and organ systems, including the placenta, female and male reproductive systems, heart muscle, immune cells, lymphatic organs, respiratory system, skin, smooth muscle and urinary tract. Gal-3 participates in numerous biological processes associated with cell growth and differentiation [9]. This protein has also been implicated in numerous clinical states, such as inflammation [10] and heart disease [11]. These two outcomes commonly accompany PE in women. Although the levels of some galectins in normal pregnant women [12] and in women with PE [13] have been studied, those of Gal-3 in patients with PE have not been examined.

A sufficient amount of $\mathrm{Ca}^{2+}$ is required for blood vessel contraction, and $\mathrm{Mg}^{2+}$ is necessary for relaxation involved in BP regulation [14]. The body uses bone tissue as a $\mathrm{Ca}^{2+}$ reservoir to maintain blood $\mathrm{Ca}^{2+}$ at levels required by muscles and intercellular fluids. Various 
cardiovascular risk factors are correlated with dietary $\mathrm{Mg}^{2+}$ intake and serum $\mathrm{Mg}^{2+}$. The presence of risk factors of PE and cardiovascular diseases, such as hypertension, smoking, diabetes and dyslipidaemia, is inversely correlated with $\mathrm{Mg}^{2+}$ levels. Specifically, most individuals with these risk factors have lower dietary and serum $\mathrm{Mg}^{2+}$ levels than those without [15].

This study aimed to determine if serum apelin and Gal-3 levels are risk factors of cardiovascular complications in Iraqi patients with PE. The correlations amongst serum apelin and Gal-3 levels with the other parameters of patients with PE were determined to obtain further insight on the pathological changes associated with PE.

\section{Materials and Methods}

A. Patients: Sixty pregnant Iraqi women with PE and the mean age of $31.65 \pm 6.30$ years were recruited from Al-Nummania Hospital, Wasit Province, Iraq and from private clinics over the period of June to September 2016. PE was diagnosed by gynaecologists in accordance with the guidelines established by the International Society for the Study of Hypertension in Pregnancy. Women with PE met at least two of the following criteria: 1) systolic $\mathrm{BP} \geq 140 \mathrm{mmHg}$ or diastolic $\mathrm{BP} \geq 90 \mathrm{mmHg}$ and 2) albumin in urine with or without oedema [16]. Most of the women with PE who participated in this study were obese and hypertensive and had proteinuria. Samples were collected from the patient and control groups after 10-12 hours of fasting. The present study was approved by the local institutional review board of the Wasit Health Department (REC number: 204/2016). All participants included in this study and their first degree relatives gave written informed consent after appropriate explanation according to the Declaration of Helsinki.

B. Controls: Thirty healthy pregnant women were selected as the control group. The mean age of women in the control group was $30.08 \pm 6.87$ years and was comparable with that of women in the PE group. Their pregnancy durations (in weeks) were the same. All of the women in the control group had normal BP. 
C. Exclusion Criteria: Women with chronic hypertension, diabetes mellitus (DM), renal disorder, autoimmune diseases and maternal infection were excluded.

\section{Measurements}

The venous blood samples of pregnant women were aspirated without tourniquet into plain tubes, allowed to stand for $10 \mathrm{~min}$ for coagulation and then separated through centrifugation at $3,000 \times g$ for $5 \mathrm{~min}$. Sera were maintained at $-18{ }^{\circ} \mathrm{C}$ until analysis. Insulin levels were measured using a ready-to-use ELISA kit supplied by Novex, USA. Gal-3 levels were measured with a ELISA kit provided by Thermo-Scientific, USA. Apelin levels were measured with an ELISA kit procured from Cloud-Clone Corp., USA. All other parameters were measured spectrophotometrically by using ready-to-use kits.

IR parameters were calculated from fasting glucose and insulin concentrations by using HOMA calculator software (http://www.dtu.ox.ac.uk/homa-calculator/download.php). This software was used to generate the IR index (HOMA2IR), insulin sensitivity index (HOMA\%S) and $\beta$-cell function index (HOMA\%B) [17].

\section{$\underline{\text { Statistical Analysis }}$}

Variable distributions were examined through the Kolmogorov-Smirnov test. Normally distributed parameters were expressed as mean \pm standard deviation. Pooled $t$-test was performed to compare the parameters of the PE and control groups. Pearson's correlation coefficients $(r)$ were calculated to estimate correlations amongst parameters. Results for nonparametric variables were expressed in the form of medians. Mann-Whitney U-test was used to compare the measured parameters of the PE and control groups. Spearman's correlation analysis was used to estimate correlations amongst parameters. Statistical differences amongst categorical variables were evaluated through $\chi^{2}$-test. Differences between groups was considered statistically significant when $\mathrm{p}<0.05$. Power analysis indicated that the total sample size should be 90 when using an effect size of $0.3, a=0.05$, power $=0.8$ and two groups. All statistical analyses were performed using SPSS Statistics version 21 (2013), IBM-USA. Figures were generated using the Excel programme of Microsoft Office 2013.

\section{$\underline{\text { Results }}$}

Comparison between PE and control groups

\section{1- Descriptive parameters}


The descriptive parameters of the PE and control groups are presented in Table 1.

Table 1: Descriptive parameters of the PE and control groups were expressed as mean \pm standard deviation. (N.S. = nonsignificant, $p>0.05)$.

\begin{tabular}{|c|c|c|c|}
\hline Parameters & Patients & Control & p-value \\
\hline Age & $31.65 \pm 6.31$ & $30.08 \pm 6.87$ & N.S. \\
\hline Duration of pregnancy wk & $27.30 \pm 5.03$ & $28.63 \pm 6.80$ & N.S. \\
\hline Abortion & $45.0 \%(27 / 60)$ & $16.7 \%(5 / 30)$ & 0.024 \\
\hline Having child & $18.3 \%(11 / 60)$ & $60.0 \%(18 / 30)$ & 0.003 \\
\hline Wt. & $86.10 \pm 10.80$ & $75.02 \pm 7.80$ & $<0.001$ \\
\hline Height & $1.55 \pm 0.20$ & $1.54 \pm 0.19$ & 0.002 \\
\hline $\mathrm{kg} / \mathrm{m}^{2}$ & $34.8 \pm 4.30$ & $30.70 \pm 3.40$ & $<0.001$ \\
\hline Sys. BP mmHg & $153.10 \pm 8.43$ & $118.62 \pm 2.24$ & $<0.001$ \\
\hline Dias. BP $\mathrm{mmHg}$ & $108.91 \pm 5.83$ & $82.64 \pm 2.07$ & $<0.001$ \\
\hline
\end{tabular}

The results indicated significantly higher abortion rates $(\mathrm{p}=0.024)$, number of live births $(\mathrm{p}$ $=0.003)$, systolic and diastolic BP $(\mathrm{p}<0.001)$ and BMI $(\mathrm{p}<0.001)$ in the PE group than in the control group.

\section{2- IR parameters}

The IR parameters of the PE and control groups are provided in Table 2.

Table 2: IR parameters of the PE and control groups. Medians in brackets. (N.S.= nonsignificant, $p>0.05$ ).

\begin{tabular}{|c|c|c|c|}
\hline Parameters & Patients & Control & p-value \\
\hline Insulin $\mathrm{mIU} / \mathrm{L}$ & $8.37 \pm 1.94$ & $8.57 \pm 1.55$ & N.S. \\
\hline FBG $\mathrm{mM}$ & $4.84 \pm 0.69$ & $3.94 \pm 0.64$ & 0.032 \\
\hline $\mathrm{I} / \mathrm{G} \quad \mathrm{IU} / \mathrm{mol}$ & $2.03 \pm 0.84$ & $2.27 \pm 0.71$ & N.S. \\
\hline HOMA $2 \%$ B & $(133.35)$ & $(118.55)$ & 0.027 \\
\hline HOMA $2 \% \mathrm{~S}$ & $99.83 \pm 18.03$ & $96.69 \pm 22.81$ & N.S. \\
\hline HOMA2IR & $1.04 \pm 0.20$ & $1.03 \pm 0.15$ & N.S. \\
\hline
\end{tabular}

The results revealed significantly higher FBG $(\mathrm{p}=0.032)$ and $\mathrm{HOMA} \% \mathrm{~B}(\mathrm{p}=0.027)$ in the PE group than in the control group.

\section{3- Lipid profile parameters}

The lipid profile parameters and atherogenic indices of the two groups are presented in Table 3.

Table 3: Lipid profiles of the PE patient and control groups. (N.S. = nonsignificant, p > 0.05). 


\begin{tabular}{|c|c|c|c|}
\hline Parameters & Patients & Control & p-value \\
\hline $\mathrm{mM}$ & $6.48 \pm 1.20$ & $4.87 \pm 0.66$ & 0.003 \\
\hline $\mathrm{mM}$ & $2.73 \pm 0.81$ & $1.46 \pm 0.42$ & $<0.001$ \\
\hline VLDLc mM & $0.54 \pm 0.16$ & $0.29 \pm 0.09$ & $<0.001$ \\
\hline HDLc $\mathrm{mM}$ & $1.28 \pm 0.16$ & $1.45 \pm 0.11$ & 0.024 \\
\hline LDLc $\mathrm{mM}$ & $3.92 \pm 1.24$ & $2.71 \pm 0.63$ & 0.004 \\
\hline LDLc/HDLc & $3.17 \pm 1.34$ & $1.89 \pm 0.56$ & $<0.001$ \\
\hline Chol/HDLc & $5.21 \pm 1.52$ & $3.39 \pm 0.64$ & 0.017 \\
\hline TG/HDL & $2.20 \pm 0.88$ & $1.01 \pm 0.28$ & 0.012 \\
\hline
\end{tabular}

Save for HCLc, which showed a significant reduction, the lipid profile parameters of the PE group were significantly higher than those of the control group ( $\mathrm{p}<0.05)$.

\section{4- Apelin levels}

Figure 1 presents the comparison between the apelin levels of the PE and control groups. The median serum apelin level of the PE group $(0.43 \pm 0.15 \mathrm{ng} / \mathrm{ml})$ was significantly lower ( $\mathrm{p}$ $<0.01)$ than that of the control group $(0.77 \pm 0.24 \mathrm{ng} / \mathrm{ml})$.

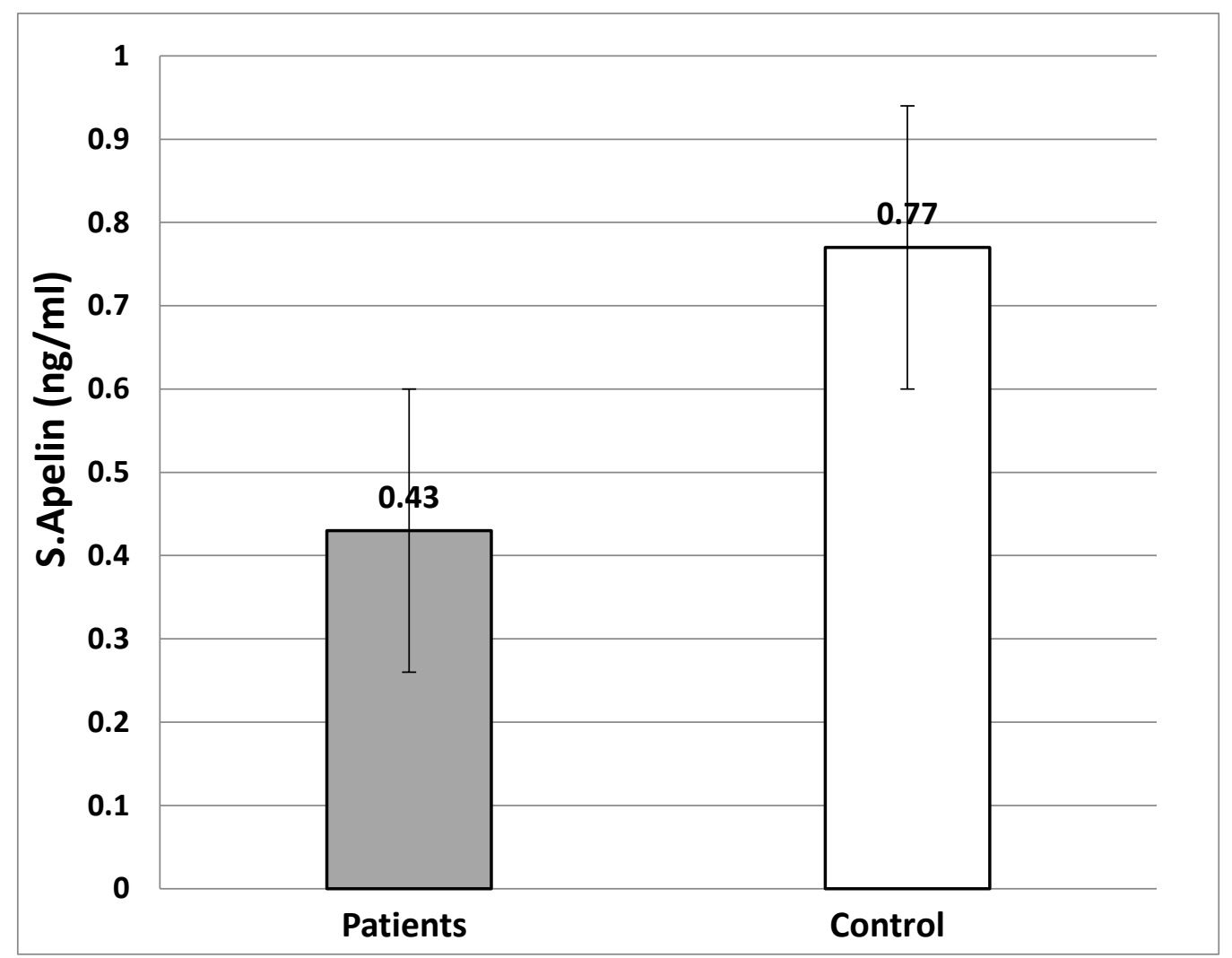

Figure 1: Median serum apelin levels of the PE and control groups. Error bars represent the $25 \%-75 \%$ percentile. 


\section{5- Gal-3 levels}

The median serum Gal-3 levels of the PE group (18.94 ng/ml) was significantly higher (p $=0.017)$ than that of the control group $(13.72 \mathrm{ng} / \mathrm{ml})$, as depicted in Figure 2 .

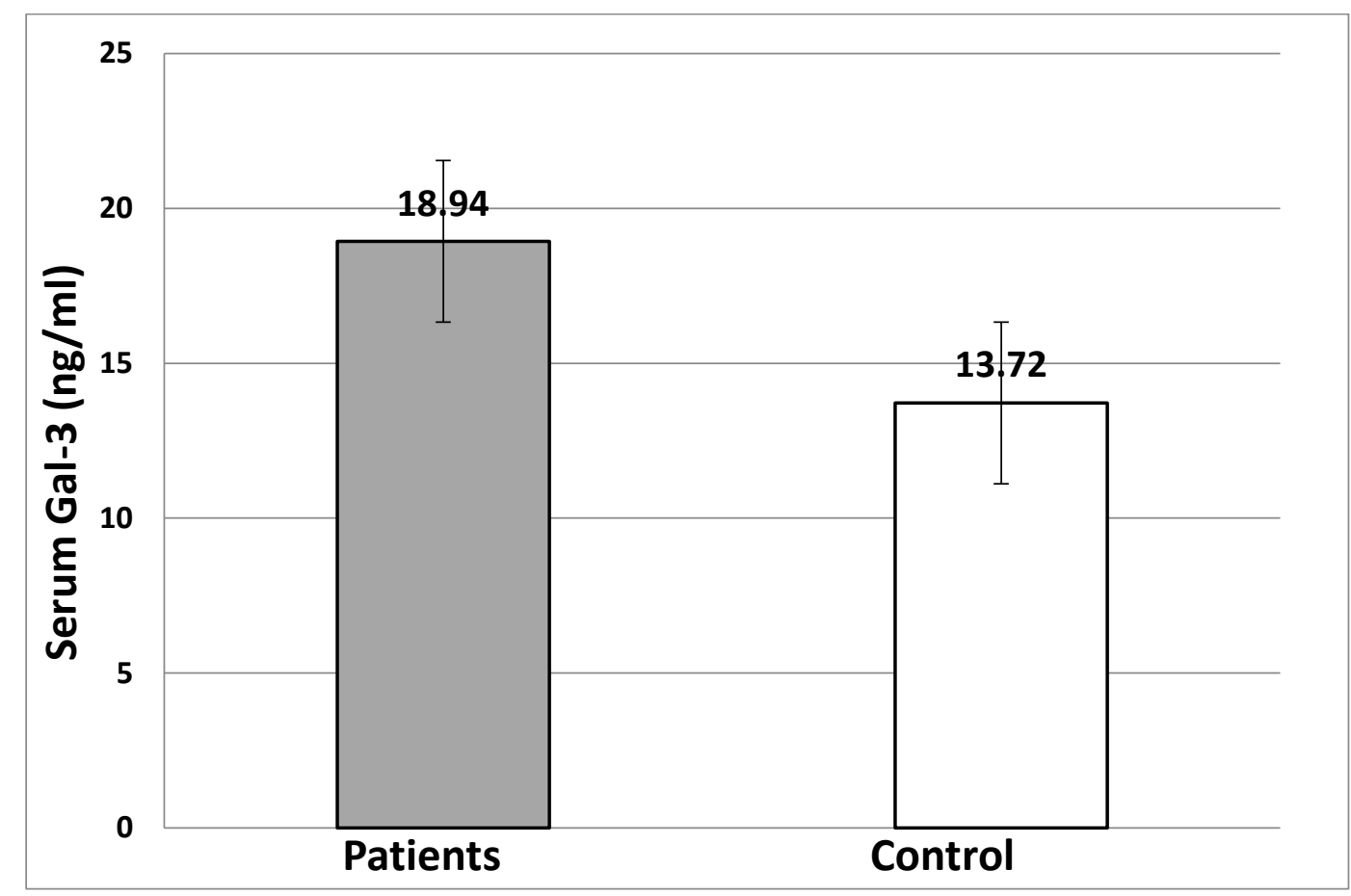

Figure 2: Serum Gal-3 levels of the PE and control groups. Error bars represent the 25\%$75 \%$ percentile.

\section{6- Serum $\mathrm{Ca}^{2+}$ and $\mathrm{Mg}^{2+}$ levels}

The total $\mathrm{Ca}^{2+}$ levels of the patient and control groups were $2.1 \pm 1.04$ and $2.09 \pm 0.10 \mathrm{mM}$, respectively $(\mathrm{p}=0.134)$. The total $\mathrm{Mg}^{2+}$ levels of the patient and control groups were $0.60 \pm$ 0.08 and $0.65 \pm 0.03 \mathrm{mM}$, respectively $(\mathrm{p}=0.037)$. The $\mathrm{Ca}^{2+} / \mathrm{Mg}^{2+}$ ratios of the patient and control groups were $3.54 \pm 1.64$ and $3.23 \pm 0.19$, respectively $(\mathrm{p}=0.035)$. The serum $\mathrm{Mg}^{2+}$ levels of the PE group were higher than those of the control group. The $\mathrm{Ca}^{2+} / \mathrm{Mg}^{2+}$ ratio of the PE group was higher than that of the control group.

\section{7- Correlations amongst apelin, Gal-3 and other parameters of patients with PE}

No significant correlation ( $\mathrm{p}>0.05$ ) was found amongst apelin levels, anthropometric parameters and any IR-associated parameter. No statistically significant difference was also observed between apelin levels and any lipid profile parameter. 
Serum Gal-3 level was significantly correlated with pregnancy duration $(\mathrm{r}=0.509, \mathrm{p}<$ $0.001)$ and age $(r=0.542, p<0.001)$. Gal-3 was significantly correlated with the following IRassociated parameters: insulin $(r=0.343, p=0.006)$, FBG $(r=0.551, p<0.001)$, HOMA2IR $(\mathrm{r}=0.448, \mathrm{p}<0.001)$ and HOMA\%S $(\mathrm{r}=0.283, \mathrm{p}=0.025)$.

The correlations between Gal-3 and lipid profile parameters were highly significant, as indicated in Table 4.

Table 4: Correlation between Gal-3 and lipid profile parameters.

\begin{tabular}{|c|c|c|c|c|c|c|c|c|c|}
\hline \multicolumn{2}{|c|}{} & VLDLc & LDLc & HDLc & TG & Chol & LDLc/HDLc & Chol/HDLc & TG/HDLc \\
\hline \multirow{2}{*}{ Gal-3 } & $\mathrm{r}$ & $0.503^{* *}$ & $0.472^{* *}$ & $-0.279^{*}$ & $0.504^{* *}$ & $0.661^{* *}$ & $0.446^{* *}$ & $0.577^{* *}$ & $0.474^{* *}$ \\
\cline { 2 - 9 } & $\mathrm{p}$ & $<0.001$ & $<0.001$ & 0.027 & $<0.001$ & $<0.001$ & $<0.001$ & $<0.001$ & $<0.001$ \\
\hline
\end{tabular}

Other parameters showed no significant correlations with the Gal-3 levels and other measured parameters of the PE group. No significant correlation was found between the apelin and Gal-3 levels of the PE group ( $\mathrm{r}=0.076, \mathrm{p}=0.551)$.

\section{$\underline{\text { Discussion }}$}

\section{1- Descriptive parameters}

The results provided in Table 1 indicate that the BMIs of the PE group were significantly higher than those of the control group as previously observed [18]. High prepregnancy BMIs have been associated with an increased risk of pregnancy-induced hypertension, stillbirth and neonatal and infant deaths, as well as increased hospitalisation length for mothers and infants [19]. The PE group had high rates of abortion, neonatal and maternal deaths, preterm deliveries and still births, as well as low birth weights [20].

\section{2- IR parameters}

Table 2 reveals that women with PE also have IR disturbances as previously reported [21]. Fasting insulin levels increase during late gestation [22]. The reliability of the HOMA-IR index in the calculation of IR has been validated [23]. HOMA calculation is a good adjunct to HbA1c and glucose testing in patients with type 2 diabetes, prediabetes or high diabetes risk due to family history or obesity. PE involves IR disturbances, especially DM [24]. Patients with PE will manifest other symptoms of metabolic syndrome after several years [25].

\section{3- Lipid profile parameters}


As reported in previous studies, patients with PE exhibit dyslipidaemia (Table 3) [26]. Dyslipidaemia and PE have a causal relationship. Early pregnancy dyslipidaemia, particularly hypertriglyceridaemia and hypercholesterolaemia, is a potential predictor of PE development and severity [27].

\section{4- Apelin levels}

As depicted in Figure 1, the apelin levels of patients with PE are lower than those of the controls $[8,28]$ given that pregnant women excrete high amounts of protein in their urine [29]. Apelin levels reflect the cardiovascular changes associated with pregnancy. The apelin levels of maternal serum and cord blood are negatively correlated with gestational age and birth weight [30]. The apelin levels of women with PE are lower than those of women without PE at the second trimester of pregnancy [31]. The lower serum apelin levels of the PE group than those of the control group may be ascribed to the elevated insulin and lipid levels of the PE group [31]. The negative regulation of apelin by angiotensin II may also account for the reduced expression of apelin in villi [7]. Patients with PE have lower placental apelin levels and higher circulating apelin levels than controls [18]. The high expression levels of apelin in PE placentas suggest that apelin may participate in the development of PE by reducing angiogenic activity during placental implantation [32]. The high apelin levels of obese patients with or without hypertension act as a compensatory mechanism against obesity-associated myocardial dysfunction [33].

\section{5- Gal-3 levels}

The Gal-3 levels of the PE group were higher than those of the control group as shown in Figure 2. The study of galectin may facilitate the prediction, presentation, diagnosis and treatment of pregnancy complications because galectins that are expressed at the maternalfoetal interface may have crucial roles in maternal-foetal interactions [34]. Immune system processes must be considered to fully explain the changes in serum Gal-3 levels given that Gal3 has numerous immunological roles. The interplay amongst lectins, including Gal-3, may participate in developmental processes and immune modulation during early pregnancy [35]. Gal-3 is a proinflammatory signal that targets diverse innate immune components (i.e. macrophages, mast cells and neutrophils) to promote immune activation, cytokine production and degranulation [36]. The expression of this protein is upregulated in the endometrium at the peri-implantation period and is detected in placental lineages as gestation progresses [37]. Therefore, the higher Gal-3 levels of the PE group than that of the control group may have an 
immunological aspect that requires extensive exploration. Venkatraman et al., showed that Gal3 is closely linked to the inflammatory cascade and could be valuable as a prognostic indicator and therapeutic target in cardiovascular disease (CVD) [38]. Pang et al. found that Gal-3 is associated with obesity and inflammation in women [39]. However, this finding is limited by the fact that their study group included nonpregnant African-American women with varying CVD risks. By contrast, the sample of the present study comprised pregnant women with PE. Another important study revealed that PE is associated with a 4-fold increase in future incidences of heart failure and a 2-fold increased risk in coronary heart disease [40]. The results of these studies and our study indicate that Gal-3 is associated with PE and is a high-risk factor of heart diseases in addition to obesity.

\section{6- Serum $\mathrm{Ca}^{2+}$ and $\mathrm{Mg}^{2+}$ levels}

A relationship exists between PE and the serum levels of electrolytes, particularly $\mathrm{Ca}^{2+}$ and $\mathrm{Mg}^{2+}$ [41]. Patients with PE have low $\mathrm{Ca}^{2+}$ and $\mathrm{Mg}^{2+}$ levels [41]. The serum $\mathrm{Ca}^{2+}$ and $\mathrm{Mg}^{2+}$ levels of the PE group were significantly lower than those of the control group. The risk factors of CVD, including age, body mass index, systolic BP, serum lipid and Ca profile, were not correlated with serum $\mathrm{Mg}^{2+}$ levels [42]. $\mathrm{Mg}^{2+}$ deficiency may be ascribed to different reasons and mechanisms, including $\mathrm{Mg}^{2+}$ redistribution, reductions in intestinal absorption and dietary intake, renal loss, alcohol consumption, endocrine causes, drugs and DM [43].

\section{Correlations amongst apelin and Gal-3 levels with other parameters of patients with PE}

The nonsignificant correlation $(\mathrm{p}>0.05)$ between apelin and the other measured parameters of the PE group (Table 4) indicates that apelin secretion is not controlled by the measured variables. Gal-3 links inflammation and reduced insulin sensitivity [44]. It can bind directly to insulin receptors and inhibit downstream receptor signalling, and the inhibition of Gal-3 may have applications in the treatment of IR [44]. The linkage amongst IR, Gal-3 and inflammation warrants further validation [45].

Gal-3 levels and lipid profile parameters showed highly significant correlations, as indicated in Table 4. Gal-3 concentrations are associated with an increased incidence of heart failure and atrial fibrillation [46]. Gal-3 may also be an important modulator of some metabolic disorders associated with cardiac disorders, such as adiposity, IR and hyperglycaemia [46]. Crosssectional analyses showed that Gal-3 is associated with abdominal adiposity, dyslipidaemia and hypertension [47]. These findings agree with the results of the present study. Further studies are necessary to obtain a comprehensive understanding of these results. 
This work is the first to reveal nonsignificant correlations between the apelin and Gal-3 levels of patients with PE. In morbidly obese patients, Gal-3 levels are associated with diastolic dysfunction. Gal-3 is a potential novel target in the treatment of obesity-associated cardiac fibrosis and inflammation. These conditions are symptoms of PE [48, 49].

\section{Conclusion}

This study elucidated the possible roles of apelin and Gal-3 in the development of the consequences of PE on heart health. Gal-3 is a more important index of the cardiac health of women with PE than apelin because it has statistically significant correlations with the IRrelated parameters and lipid profiles of patients with PE. Elevations in serum Gal-3 are correlated with increments in IR-associated parameters and lipid profiles.

\section{$\underline{\text { Acknowledgement }}$}

We are grateful to University of Kashan for supporting this work.

References

[1] N. Al-Jameil, F.A. Khan, M.F. Khan, H. Tabassum, A brief overview of preeclampsia, Journal of clinical medicine research 6(1) (2014) 1.

[2] H.K.R. Riise, G. Sulo, G.S. Tell, J. Igland, O. NygAard, S.E. Vollset, A.C. Iversen, R. Austgulen, A.K. Daltveit, Incident coronary heart disease after preeclampsia: role of reduced fetal growth, preterm delivery, and parity, Journal of the American Heart Association 6(3) (2017) e004158.

[3] L.O. Perucci, M.D. Corrêa, L.M. Dusse, K.B. Gomes, L.P. Sousa, Resolution of inflammation pathways in preeclampsia - a narrative review, Immunologic research 65(4) (2017) 774-789.

[4] C. Galanth, A. Hus-Citharel, B. Li, C. Llorens-Cortes, Apelin in the control of body fluid homeostasis and cardiovascular functions, Current pharmaceutical design 18(6) (2012) 789-798.

[5] L. Li, G. Yang, Q. Li, Y. Tang, M. Yang, H. Yang, K. Li, Changes and relations of circulating visfatin, apelin, and resistin levels in normal, impaired glucose tolerance, and type 2 diabetic subjects, Experimental and Clinical Endocrinology \& Diabetes 114(10) (2006) 544-548.

[6] J.S. Gilbert, From apelin to exercise: emerging therapies for management of hypertension in pregnancy, Hypertension Research 40(6) (2017) 519.

[7] L.M. Yamaleyeva, M.C. Chappell, K.B. Brosnihan, L. Anton, D.L. Caudell, S. Shi, C. McGee, N. Pirro, P.E. Gallagher, R.N. Taylor, Downregulation of apelin in the human placental chorionic villi from preeclamptic pregnancies, American Journal of Physiology-Endocrinology and Metabolism 309(10) (2015) E852-E860.

[8] T. Van Mieghem, A. Doherty, D. Baczyk, S. Drewlo, D. Baud, J. Carvalho, J. Kingdom, Apelin in normal pregnancy and pregnancies complicated by placental insufficiency, Reproductive Sciences 23(8) (2016) 1037-1043. 
[9] J. Dumic, S. Dabelic, M. Flögel, Galectin-3: an open-ended story, Biochimica et Biophysica Acta (BBA)-General Subjects 1760(4) (2006) 616-635.

[10] L. Agnello, G. Bivona, B.L. Sasso, C. Scazzone, V. Bazan, C. Bellia, M. Ciaccio, Galectin-3 in acute coronary syndrome, Clinical biochemistry 50(13-14) (2017) 797-803.

[11] B.R. Gittens, J.V. Bodkin, S. Nourshargh, M. Perretti, D. Cooper, Galectin-3: a positive regulator of leukocyte recruitment in the inflamed microcirculation, The Journal of Immunology (2017) 1600709.

[12] E.A.L. Enninga, S.M. Harrington, D.J. Creedon, R. Ruano, S.N. Markovic, H. Dong, R.S. Dronca, Immune checkpoint molecules soluble program death ligand 1 and galectin-9 are increased in pregnancy, American Journal of Reproductive Immunology 79(2) (2018) e12795.

[13] E. Menkhorst, K. Koga, M. Van Sinderen, E. Dimitriadis, Galectin-7 serum levels are altered prior to the onset of pre-eclampsia, Placenta 35(4) (2014) 281-285.

[14] E. Idogun, C. Imarengiaye, S. Momoh, Extracellular calcium and magnesium in preeclampsia and eclampsia, African Journal of Reproductive Health 11(2) (2007) 89-94.

[15] N. Mahalle, S.S. Naik, M.V. Kulkarni, Is hypomagnesaemia a coronary risk factor among Indians with coronary artery disease?, Journal of cardiovascular disease research 3(4) (2012) 280-286.

[16] A.C.o.O. Practice, ACOG practice bulletin. Diagnosis and management of preeclampsia and eclampsia. Number 33, January 2002. American College of Obstetricians and Gynecologists, International journal of gynaecology and obstetrics: the official organ of the International Federation of Gynaecology and Obstetrics 77(1) (2002) 67.

[17] H.K. Al-Hakeim, M.S. Abdulzahra, Correlation Between Glycated Hemoglobin and Homa Indices in Type 2 Diabetes Mellitus: Prediction of Beta-Cell Function from Glycated Hemoglobin/Korelacija Između Glikoliziranog Hemoglobina I Homa Indeksa U Dijabetes Melitusu Tipa 2: Predviđanje Funkcije Beta Ćelija Na Osnovu Glikoliziranog Hemoglobina, Journal of medical biochemistry 34(2) (2015) 191-199.

[18] A. Molvarec, Z. Prohászka, B. Nagy, L. Kalabay, J. Szalay, G. Füst, I. Karádi, J. Rigó Jr, Association of increased serum heat shock protein 70 and C-reactive protein concentrations and decreased serum a2-HS glycoprotein concentration with the syndrome of hemolysis, elevated liver enzymes, and low platelet count, Journal of reproductive immunology 73(2) (2007) 172-179.

[19] H.S.C.R. Group, Hyperglycaemia and Adverse Pregnancy Outcome (HAPO) Study: associations with maternal body mass index, BJOG: An International Journal of Obstetrics \& Gynaecology 117(5) (2010) 575-584.

[20] Y.-y. Su, J.-z. Zhang, F. Wang, Risk factors and adverse outcomes of preeclampsia: a tertiary care centrebased study in China, Biomedical Research 28(3) (2017).

[21] K.H. Lampinen, M. Rönnback, P.-H. Groop, R.J. Kaaja, A relationship between insulin sensitivity and vasodilation in women with a history of preeclamptic pregnancy, Hypertension 52(2) (2008) 394401.

[22] M. Prieto, F.M. Diez, M. Arevalo, R.E. Salido, A. Torres, PMC3668662, J Clin Invest 123(7) (2013) 3124-34.

[23] P. Beck, W.H. Daughaday, Human placental lactogen: studies of its acute metabolic effects and disposition in normal man, The Journal of clinical investigation 46(1) (1967) 103-110.

[24] P. Wu, C.S. Kwok, R. Haththotuwa, R.A. Kotronias, A. Babu, A.A. Fryer, P.K. Myint, C.A. ChewGraham, M.A. Mamas, Pre-eclampsia is associated with a twofold increase in diabetes: a systematic review and meta-analysis, Diabetologia 59(12) (2016) 2518-2526.

[25] M.M. Rice, M.B. Landon, M.W. Varner, B.M. Casey, U.M. Reddy, R.J. Wapner, D.J. Rouse, J.R. Biggio Jr, J.M. Thorp Jr, E.K. Chien, Pregnancy-associated hypertension in glucose intolerant pregnancy and subsequent metabolic syndrome, Obstetrics and gynecology 127(4) (2016) 771.

[26] S. Timalsina, P. Gyawali, A. Bhattarai, Comparison of lipid profile parameters and oxidized lowdensity lipoprotein between normal and preeclamptic pregnancies in a tertiary care hospital in Nepal, International journal of women's health 8 (2016) 627.

[27] N.I. El Khouly, Z.F. Sanad, S.A. Saleh, A.A. Shabana, A.F. Elhalaby, E.E. Badr, Value of firsttrimester serum lipid profile in early prediction of preeclampsia and its severity: A prospective cohort study, Hypertension in pregnancy 35(1) (2016) 73-81.

[28] H. Inuzuka, H. Nishizawa, A. Inagaki, M. Suzuki, S. Ota, H. Miyamura, J. Miyazaki, T. Sekiya, H. Kurahashi, Y. Udagawa, Decreased expression of apelin in placentas from severe pre-eclampsia patients, Hypertension in pregnancy 32(4) (2013) 410-421. 
[29] H.K. Al-Hakeim, R.A.M. Ali, Proteinuria as the most relevant parameter affecting Fetuin-A levels in preeclampsia, Acta facultatis medicae Naissensis 32(4) (2015) 267-277.

[30] M. Aslan, O. Celik, N. Celik, I. Turkcuoglu, E. Yilmaz, A. Karaer, Y. Simsek, E. Celik, S. Aydin, Cord blood nesfatin-1 and apelin-36 levels in gestational diabetes mellitus, Endocrine 41(3) (2012) 424429.

[31] A. Kourtis, A. Gkiomisi, M. Mouzaki, K. Makedou, A.D. Anastasilakis, K.A. Toulis, S. Gerou, E. Gavana, T. Agorastos, Apelin levels in normal pregnancy, Clinical endocrinology 75(3) (2011) 367371.

[32] L. Cobellis, M. De Falco, A. Mastrogiacomo, D. Giraldi, D. Dattilo, C. Scaffa, N. Colacurcl, A. De Luca, Modulation of apelin and APJ receptor in normal and preeclampsia-complicated placentas, Histology and histopathology 22(1-3) (2007) 1-8.

[33] S. Suzuki, Y. Hiraizumi, M. Satomi, History of abortion and perinatal outcomes associated with preeclampsia in nulliparous Japanese women, The Journal of Maternal-Fetal \& Neonatal Medicine 23(11) (2010) 1318-1319.

[34] A. Than, Y. Cheng, L.-C. Foh, M.K.-S. Leow, S.C. Lim, Y.J. Chuah, Y. Kang, P. Chen, Apelin inhibits adipogenesis and lipolysis through distinct molecular pathways, Molecular and cellular endocrinology 362(1) (2012) 227-241.

[35] M.V. Tribulatti, M.G. Figini, J. Carabelli, V. Cattaneo, O. Campetella, Redundant and antagonistic functions of galectin-1,-3, and-8 in the elicitation of $\mathrm{T}$ cell responses, The Journal of Immunology (2012) 1102182.

[36] C.M. Alves, D.A. Silva, A.E.C. Azzolini, C.M. Marzocchi-Machado, J.V. Carvalho, A.C.A. Pajuaba, Y.M. Lucisano-Valim, R. Chammas, F.-T. Liu, M.C. Roque-Barreira, Galectin-3 plays a modulatory role in the life span and activation of murine neutrophils during early Toxoplasma gondii infection, Immunobiology 215(6) (2010) 475-485.

[37] S.M. Blois, G. Barrientos, Galectin signature in normal pregnancy and preeclampsia, Journal of reproductive immunology 101 (2014) 127-134.

[38] A. Venkatraman, S. Hardas, N. Patel, N. Singh Bajaj, G. Arora, P. Arora, Galectin-3: an emerging biomarker in stroke and cerebrovascular diseases, European journal of neurology 25(2) (2018) 238-246.

[39] J. Pang, V. Nguyen, D. Rhodes, M. Sullivan, C. Braunschweig, G. Fantuzzi, Relationship of galectin3 with obesity, IL-6, and CRP in women, Journal of endocrinological investigation 39(12) (2016) 14351443.

[40] P. Wu, R. Haththotuwa, C.S. Kwok, A. Babu, R.A. Kotronias, C. Rushton, A. Zaman, A.A. Fryer, U. Kadam, C.A. Chew-Graham, Preeclampsia and future cardiovascular health: a systematic review and meta-analysis, Circulation: Cardiovascular Quality and Outcomes 10(2) (2017) e003497.

[41] A. Abdellah, A. Abdrabo, Assessment of serum calcium, magnesium, copper and zinc levels in Sudanese pregnant women with preeclampsia, Glo Adv Res J Med Sci 3(2) (2014) 33-36.

[42] M.R. Khatami, E. Mirchi, Z. Khazaeipour, A. Abdollahi, A. Jahanmardi, Association between serum magnesium and risk factors of cardiovascular disease in hemodialysis patients, Iran J Kidney Dis 7(1) (2013) 47-52.

[43] W. Fawcett, E. Haxby, D. Male, Magnesium: physiology and pharmacology, British journal of anaesthesia 83(2) (1999) 302-320.

[44] P. Li, S. Liu, M. Lu, G. Bandyopadhyay, D. Oh, T. Imamura, A.M. Johnson, D. Sears, Z. Shen, B. Cui, Hematopoietic-derived galectin-3 causes cellular and systemic insulin resistance, Cell 167(4) (2016) 973-984. e12.

[45] M. Siwicki, C. Engblom, M.J. Pittet, Gal3 links inflammation and insulin resistance, Cell metabolism 24(5) (2016) 655-656.

[46] J.E. Ho, C. Liu, A. Lyass, P. Courchesne, M.J. Pencina, R.S. Vasan, M.G. Larson, D. Levy, Galectin3 , a marker of cardiac fibrosis, predicts incident heart failure in the community, Journal of the American College of Cardiology 60(14) (2012) 1249-1256.

[47] M. Nayor, N. Wang, M.G. Larson, R.S. Vasan, D. Levy, J.E. Ho, Circulating Galectin-3 Is Associated With Cardiometabolic Disease in the Community, Journal of the American Heart Association 5(1) (2015) e002347.

[48] S. Menini, C. Iacobini, C. Blasetti Fantauzzi, C.M. Pesce, G. Pugliese, Role of galectin-3 in obesity and impaired glucose homeostasis, Oxidative medicine and cellular longevity 2016 (2016). 
[49] E. Martínez-Martínez, N. López-Ándres, R. Jurado-López, E. Rousseau, M.V. Bartolomé, A. Fernández-Celis, P. Rossignol, F. Islas, A. Antequera, S. Prieto, Galectin-3 participates in cardiovascular remodeling associated with obesity, Hypertension (2015) HYPERTENSIONAHA. 115.06032 . 